\title{
PET and P300 Relationships in Early Alzheimer's Disease
}

\author{
JAMES T. MARSH, $*^{1}$ GLENA SCHUBARTH, $†$ WARREN S. BROWN,$*_{\ddagger}^{\ddagger}$ \\ WALTER RIEGE,*§ ROBERT STRANDBURG,*\# DEBORAH DORSEY, \\ ADRIANNE MALTESE AND DAVID KUHL** \\ *Department of Psychiatry and Biobehavioral Science and Brain Research Institute \\ University of California, Los Angeles, $C A$ \\ $\dagger$ Eastern Nazarene College, Quincy, MA \\ $\ddagger$ Graduate School of Psychology, Fuller Theological Seminary, Pasadena, CA \\ $\S V . A$. Medical Center, Sepulveda, CA \\ \#Department of Psychology, Rhodes College, Memphis, TN \\ TCenter for the Health Sciences, University of California, Los Angeles, CA \\ **Division of Nuclear Medicine, University of Michigan Hospital, Ann Arbor, MI
}

Received 1 May 1989; Accepted 11 December 1989

\begin{abstract}
MARSH, J. T., G. SCHUBARTH, W. S, BROWN, W. RIEGE, R. STRANDBURG, D. DORSEY, A. MALTESE AND D. KUHL. PET and P300 relationships in early Alzheimer's disease. NEUROBIOL AGING 11(4) 471-476, 1990. - The P300 (P3) wave of the auditory brain event-related potential was investigated in patients with probable Alzheimer's disease to determine whether P300 latency discriminated these patients from controls and whether prolonged P300 latency correlated with rates of brain glucose metabolism as measured by Positron Emission Tomography. P300 latency was prolonged by more than 1.5 standard deviations from age expectancy in 14 of 18 patients, but none of 17 controls. In these subjects P300 latency was shown to be inversely correlated with relative metabolic rates of parietal and, to a lesser extent, temporal and frontal association areas, but not with subcortical areas.
\end{abstract}

Alzheimer's disease Event-related potentials P300 Positron Emission Tomography

THE latency of the P300 (or P3) component of the brain event-related potential (ERP) has been demonstrated to increase with aging in normal adults $(2,4,13,34,38,41)$. A number of studies have also shown $\mathrm{P} 300$ latency to be significantly prolonged in dementia of varying etiology. Depending on the study, from 50 to $80 \%$ of demented patients have P300 latencies prolonged more than 2 standard deviations beyond that which would be predicted by the linear regression of $\mathrm{P} 300$ on the age of nondemented adults $(3,12,14,17-19,48)$. Further, $\mathrm{P} 300$ latency has been shown to track changes in mental status in patients whose confusional state or dementing illness varied in severity over time, increasing as dementia worsens and decreasing with remission (16). However, some investigators have questioned whether this measure is sufficiently sensitive to hold any promise for clinical diagnostic utility (35).

$\mathrm{P} 300$ latency is a measure of cognitive processing time $(8,30$, $47)$ and increases with task difficulty $(5,10,15,27,44,45)$. However, the neural substrates of abnormal P300 latency are unknown. For example, in patients with probable Alzheimer's disease, it is not known whether or not the abnormally prolonged
$\mathrm{P} 300$ latency in the majority of these patients is associated with functional deficits in specific brain regions. The opportunity to address this question arose when brain event-related potentials were obtained from patients with early probable Alzheimer's disease who were participating in a larger study to determine PET markers of probable Alzheimer's disease (pAD). Glucose utilization indexed by the uptake of (F-18) 2-fluoro-2-deoxy-glucose has been shown to be sensitive to focal changes in brain function associated with degenerative diseases of the nervous system (28, $37,42)$.

This report demonstrates not only the sensitivity of P300 latency to early stages of $\mathrm{pAD}$, but also a strong relationship between P300 latency and metabolic rate of parietal, frontal, and temporal cortical regions which are reduced in varying degrees in pAD $(7,11,29,43)$.

\section{METHOD}

Eighteen individuals with early probable Alzheimer's disease were compared with 17 age-matched healthy, nondemented individuals in this study. pAD subjects were selected from a much

\footnotetext{
'Requests for reprints should be addressed to James T. Marsh, Ph.D., Department of Psychiatry and Biobehavioral Science, UCLA School of Medicine, Los Angeles, CA 90024.
} 
larger group of over 300 individuals referred from the community on the basis of criteria characteristic of possible early Alzheimer's disease. Patients were included in the study if they met the following criteria: between 50 and 75 years of age, gradual and progressive loss of memory and cognitive function with inconspicuous onset, normal consciousness, and impairment in 3 of 5 cognitive functions (orientation, judgement and problem solving, social functioning, home and hobbies, personal care). Patients and controls were excluded from the study if there was evidence of any other neurological disorder. Information for diagnosis and inclusion in this study was obtained using a three-stage diagnostic process: 1) Preliminary Evaluation: Extended interview of subject and family members regarding education and occupational background, and medical and neurological history. Administration of several scales and tests including the Mini-Mental State, WAIS Digit Span, Word Generation, Zung Depression Scale, Blessed Dementia Scale, and Hachinski Scale. 2) Psychiatric, Neuropsychological and Neurolinguistic Evaluation: Psychiatric interview; neuropsychological evaluation of memory, intelligence, problem solving, abstraction and spatial relations; neurolinguistic evaluation of comprehension, expression, word knowledge, and writing; and completion of a Clinical Dementia Rating (23) based on all the above data. 3) Laboratory Tests and Complete Neurological Exam: Neurological examination including mental status, systems review, and vital signs; review of laboratory measures; and completion of second Hachinski Scale and Clinical Dementia Rating based on these data.

Diagnosis of pAD was confirmed on the basis of subsequent annual follow-up examinations for up to 4 years after the initial study. These diagnostic tests served to establish the presence and severity of dementia, and to rule out diagnoses other than Alzheimer's disease. Out of an initial group of 32 patients originally diagnosed as questionable $\mathrm{AD}$, the 18 subjects of this study were confirmed to be probable $\mathrm{AD}$ at follow-up 1 to 2 years later. Basis for post hoc elimination from this study was evidence of pseudodementia, atypical course, and indications of multiple infarct. Twelve of the 18 pAD patients and all 17 controls were also included in a longitudinal study of P300 latency in dementia (1).

Under the criteria of the Clinical Dementia Rating, 9 patients were given a rating of CDR 0.5 (questionable dementia) and 9 patients a CDR of 1.0 (mild dementia) at the time of original examination. Patients in this study had a mean age of $65.2 \pm 5.8$ years (standard deviation) and a mean Mini-Mental State [MMS; (8)] score of $24.7 \pm 1.3$. The 17 age-matched control persons had a mean age of $64.4 \pm 6.7$ and a mean MMS of 29.6 \pm 0.7 .

Each patient and control underwent PET scans of cerebral glucose utilization involving the injection of (F-18)-labeled 2fluoro-2-deoxy-glucose (FDG) (37). Local cerebral metabolic utilization of glucose was measured following Sokoloff's model (46). This study utilized a third generation tomograph (NeuroEcat, CTI Inc., Knoxville, TN), which has image resolution of $9.5 \mathrm{~mm}$ in the plane of section and $12.4 \mathrm{~mm}$ in the axial direction. Subjects remained in the resting state (eyes and ears open) on the gurney of the tomograph after injection of $5-10 \mathrm{mCi}$ FDG intravenously. Arteriolized blood was sampled and, after $40 \mathrm{~min}$, multiple scans were taken at 0 degrees to the orbital-meatal lines and were completed after an accumulation of 2-3 million counts per image. Image values were converted to regional cerebral metabolic rate of glucose utilization (rCMRGlu) based on the model of Phelps and Huang using constants derived from young adults (36). These rCMRGlu (in micromoles/min $/ 100$ grams) did not significantly differ from those of a group of old persons (20). If the rCMRGlu is a measure of the function of a specific region, then the cross-sectional image of the brain FDG metabolism presents a functional map of brain activity in regions of interest.
Based on hypotheses concerning possible neural systems which might modulate P300 latency (parahippocampal region), together with evidence regarding decreased function of temporal, parietal and to a lesser extent frontal cortex in moderately demented Alzheimer's patients $(11,42,43)$, we selected posterior parietal, temporal, parahippocampal and frontal PET measures reconstructed from multiple scans in the horizontal plane. Relationships between P300 latency and subcortical function were investigated using a mean of PET values from the caudate and thalamus regions (caudate-thalamus). In order to control for individual differences in overall brain metabolic rate and more specifically observe distributions of neural activity, PET measures from areas of interest were expressed as a ratio of regional to cerebellar metabolic rate. Cerebellar metabolism is known to be little affected in the early stages of Alzheimer's type dementia (25).

For $\mathrm{P} 300$ recording, individuals listened to a series of moderate intensity, low pitched tones $(250 \mathrm{~Hz}, 70 \mathrm{~dB}$ SPL, $55 \mathrm{msec}$ in duration, $1.5 \mathrm{sec}$ ISI) occasionally and randomly replaced by a higher pitched, louder tone $(450 \mathrm{~Hz}, 84 \mathrm{~dB}$, occurring on $20 \%$ of trials). Subjects were asked to keep a cumulative count of the target tones (32 in all).

ERPs were recorded from midline parietal $(\mathrm{Pz})$, central $(\mathrm{Cz})$ and frontal (Fz) scalp positions referenced to the left ear, the right ear serving as ground. EEG was amplified with gain of 14,140 and filtered at 0.1 to $50 \mathrm{~Hz}$ ( $3 \mathrm{~dB}$ down). Responses were digitized for computer averaging at 250 samples per second. ERPs were averaged over a one-second epoch, including $100 \mathrm{msec}$ of prestimulus baseline and $900 \mathrm{msec}$ of ERP. Automatic artifact rejection of single trial responses was accomplished via an amplitude window set independently for each subject. Amplitude criteria were set to reject large voltage deflections such as eye-movement and eye-blink artifact apparent in simultaneous EEG records.

The $\mathrm{P} 300$ wave was identified as the largest positive wave 280 msec or longer stimulus onset, present in responses to the target (counted) stimuli and absent (or considerably attenuated) in responses to the frequent (noncounted) stimuli. P300 latency was measured at $\mathrm{Pz}$, using the other electrodes to help identify the P300 wave. Latency was measured from the midpoint of a horizontal line drawn between the rise and fall of the wave at approximately the $2 / 3$ amplitude level. Since P300 latency increases in a systematic way with age, latency was expressed in standard deviation units (Z-scores) from the P300 latency/age regression line calculated from a group of 57 normal individuals over the age of 50 previously run in our laboratory using the same stimulus and recording parameters (4). The regression formula used to calculate the expected normal P300 latency in milliseconds was:

$$
\text { expected }=(\text { age } \times 2.05)+199
$$

\section{Z-scores were calculated using the following formula:}

$$
\mathrm{Z}=(\text { actual }- \text { expected }) / 25.3
$$

Statistical analysis of the data utilized $t$-tests, Pearson correlation, multiple regression and stepwise discriminant function analysis as appropriate. To calculate the .01 significance level adjusted for the number of correlations performed (shown as the dashed line in Fig. 3), a critical r-value was obtained by dividing the significance level of .01 by the number of comparisons. This yielded a normalized probability density value. To make this a two-tailed test of significance, that value was halved and the corresponding $t$-value obtained. The $t$-value was converted into a critical r-value using a formula given on p. 661 of (21). 
CONT: $P 3<340 \mathrm{msec}$ CONT: $P 3>340 \mathrm{msec}$ PAD: $P 3<40 D \mathrm{msec} \quad$ PAD: $P 3>400 \mathrm{msec}$

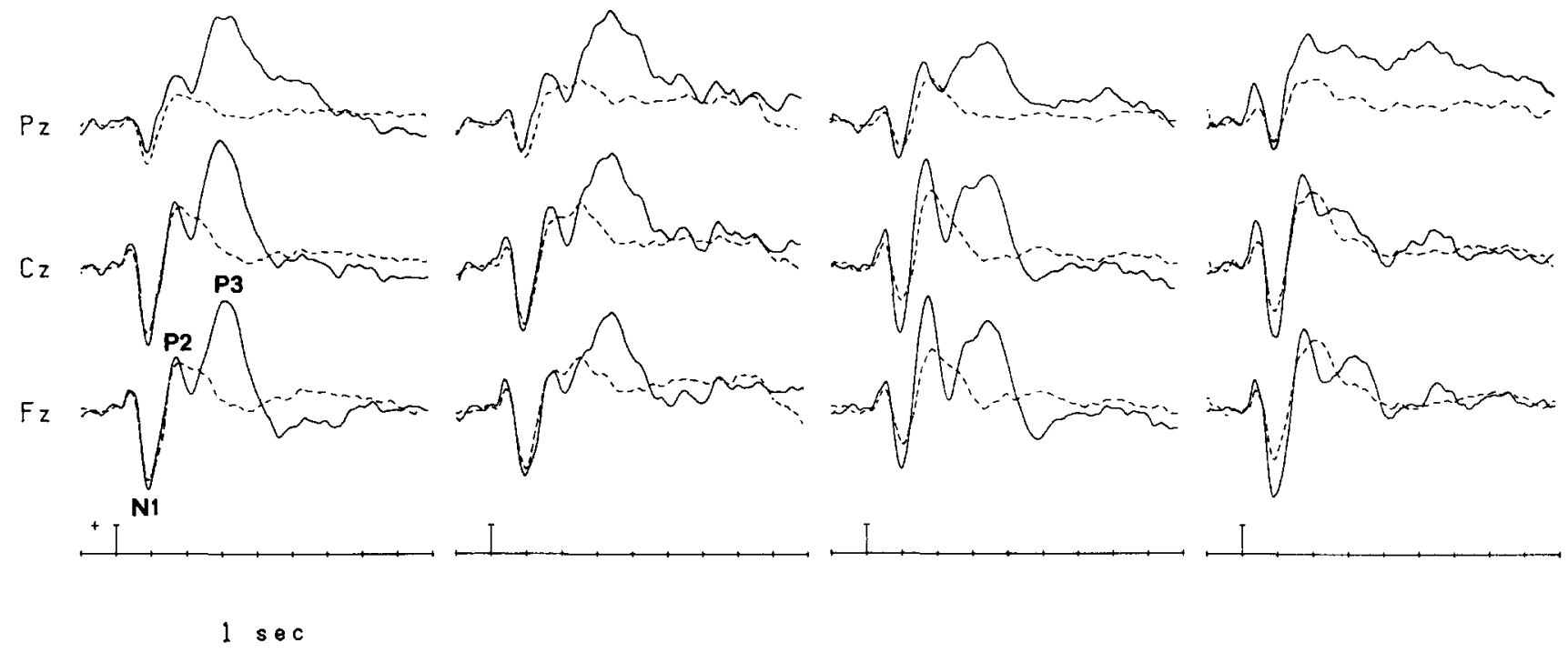

FIG. 1. Cross-subject mean ERPs based on a P300 latency median split of subjects in each group: Controls with P300 latency less than ( $N=9)$, and greater than $(\mathrm{N}=8), 340 \mathrm{msec}$; pAD subjects with latencies less than $(\mathrm{N}=9)$ and greater than $(\mathrm{N}=9) 400$ msec. Responses to the frequent (dashed) and target (solid) stimuli are superimposed for each of 3 electrode locations ( $\mathrm{Pz}, \mathrm{Cz}, \mathrm{Fz}$ ). The P300 (labeled as "P3") is evident as the positivity (upward deflection) beginning approximately $250 \mathrm{msec}$ after the tone onset (vertical marker on the time scale). Since amplitude for each subject was normalized before creating these cross-subject averages, amplitude differences between groups are not represented. However, frequent/rare amplitude relations and scalp topography $(\mathrm{Pz}, \mathrm{Cz}, \mathrm{Fz})$ are preserved. Normalization of amplitude for this figure was done to allow equal contribution of each subject to the cross-subject mean waveforms and, thus, more precise representation of the mean latency of components. Time scale tick-marks occur every $100 \mathrm{msec}$.

\section{RESULTS}

Figure 1 presents examples of ERPs from 2 normal and 2 demented individuals, illustrating longer latencies for the pAD subjects. P300 latencies in standard deviation units (Z-scores) for all normal $(C D R=0)$ and pAD patients (CDR 0.5 and 1.0) are presented in Fig. 2. The P300 latency of all 17 normal subjects fell within \pm 1.5 standard deviations of our $\mathrm{P} 300$ latency/age regression line. However, 14 of 18 pAD patients had P300 latencies

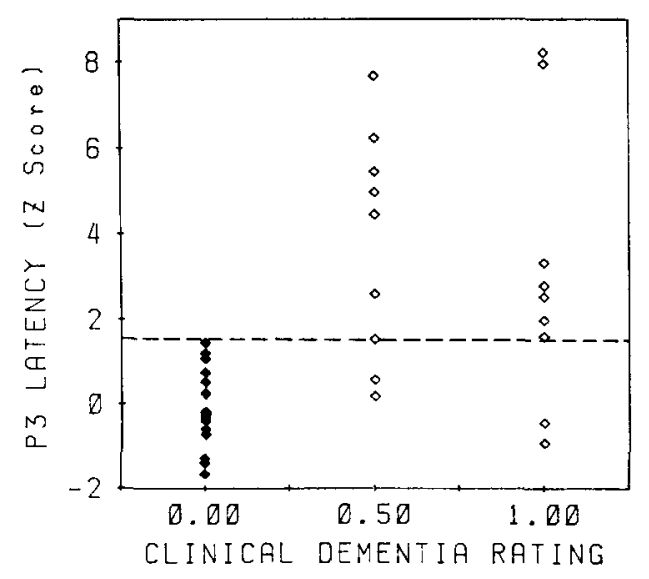

FIG. 2. P3 latency data converted to Z-scores for all subjects. From the left, columns are 17 normal controls $(C D R=0.0), 9$ questionable dementia $(C D R=0.5)$, and 9 mild dementia $(C D R=1.0) A D$ patients. The dashed line represents the maximum $Z$-score value for the normal controls of this study. Only four of 18 patients fall within the range of normal subjects. beyond the range of $\mathrm{P} 300$ latencies (in $\mathrm{Z}$-scores) for the normal group. There was a highly significant difference between normal and pAD subjects in both mean P300 latency Z-score $(t=4.86$, $p<0.0001$; normal mean $=-0.08 ;$ pAD mean $=3.37$ ) and in actual P300 latency $(t=4.95, p<0.0001$; normal mean $=335$ msec; pAD mean $=431 \mathrm{msec}$ ).

In order to test the ability of $\mathrm{P} 300$ latency to distinguish between early AD patients and normal controls, a stepwise discriminant function analysis was performed with $\mathrm{P} 300$ latency $\mathrm{Z}$-score and PET ratio values as variables. The first variable entered was P300 latency Z-score, which yielded a $89 \%$ correct classification with no controls classified as $A D$, and four $A D$ misclassified as controls. When the Parietal/Cerebellum metabolic measure was added to the discriminant function, the correct classification increased to $91.4 \%$ with one false positive, i.e., one control classified as AD. This level of discrimination is notable in view of the fact that the patients in this study were initially classified (i.e., at time of $\mathrm{P} 300$ and PET measurement) as questionable Alzheimer's disease, having symptomatology characteristic of the very early stages of dementia.

While the groups differed significantly in P3 latency, no difference was seen for the earlier N1 and P2 components. N1 latencies for the pAD and control groups were $99.3 \mathrm{msec}$ and 99.5 msec, respectively $(t=0.06, p=\mathrm{ns})$. P2 latencies were 177.3 $\mathrm{msec}$ and $182.2 \mathrm{msec}(t=0.88, p=\mathrm{ns})$.

Within the pAD group, P300 latency did not differ significantly according to CDR grouping (CDR 0.5; mean Z-score $=3.12$, mean latency $=420 \mathrm{msec}$; CDR 1.0 ; mean Z-score $=3.57$, mean latency $=440 \mathrm{msec}$ ). A relationship was found between P300 latency and scores on the Mini-Mental State Exam. For the combined group of patients and normals, there was a significant correlation between P300 latency and MMS scores (MMS vs. P300 Z-score, $\mathrm{r}=-.58, p<0.001$; MMS vs. P300 latency, 


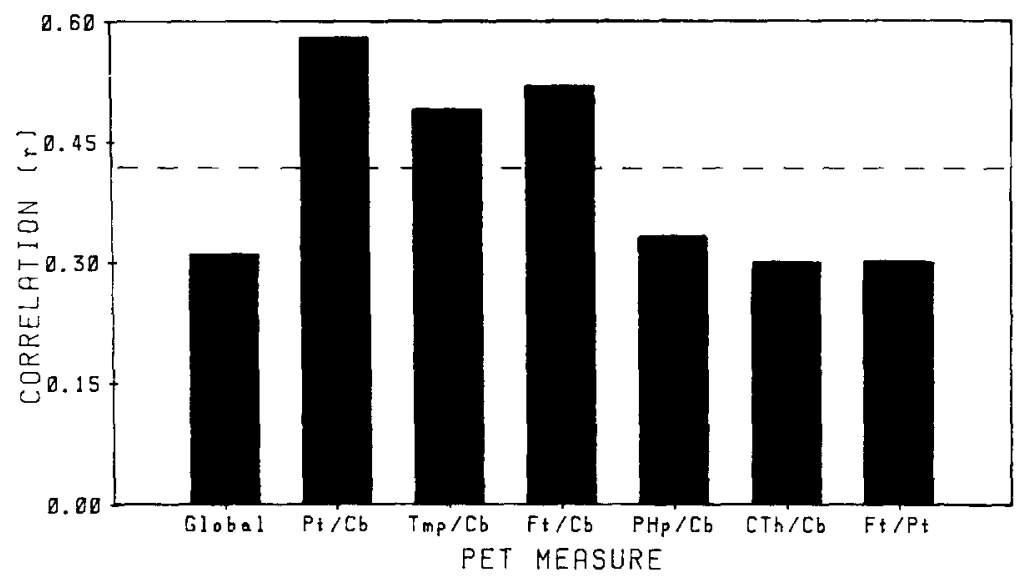

FIG. 3. Correlation of $P 3$ latency (in Z-scores) with PET measures for the combined $\mathrm{pAD}$ and control groups. From left to right, bars represent correlations with the following PET measures: global metabolic rate; parietal metabolic rate divided by cerebellum metabolic rate $(\mathrm{P} t / \mathrm{Cb})$; temporal divided by cerebellum $(\mathrm{Tmp} / \mathrm{Cb})$; frontal divided by cerebellum (Ft/Cb); parahippocampal divided by cerebellum $(\mathrm{PHp} / \mathrm{Cb})$; caudate-thalamus divided by cerebellum $(\mathrm{CTh} / \mathrm{Cb})$; and frontal divided by parietal $(\mathrm{Ft} / \mathrm{Pt})$. All correlations are graphed as absolute values. (As predicted, all correlations are negative with the exception of $\mathrm{Ft} / \mathrm{Pt}$. which is positive.) The dashed line represents the two-tailed $p<0.01$ significance level, adjusted for multiple comparisons, as described in the Method section.

$\mathrm{r}=-.61, p<0.001)$. However, within the $\mathrm{pAD}$ group itself, there was not a significant correlation between P300 Z-score and MMS. Thus, while P300 latency was indicative of the presence of pAD, even in the early mild phases, it was not consistently related to the degree of dementia as indexed either by CDR or MMS scores.

Correlations were calculated for the present data between the P300 latency Z-score vs. PET measures for various cortical and subcortical areas in the combined pAD and control group (Fig. 3). P300 latency was not correlated with global metabolic rate or with that of caudate-thalamic regions. However, significant correlations were observed in metabolic rates of cortical regions expressed as ratios of cerebellar metabolism. The parietal ratio showed the most significant negative correlation $(\mathrm{r}=-.58$, $p<0.001$; see Fig. 4), i.e., lower FDG uptake was associated with longer P300 latency. Progressively lower but significant negative correlations were found with frontal and temporal ratios. When combined into a multiple regression equation, PET measures accounted for a significant amount of variance in P300 latency $\mathrm{Z}$-scores $\left(\mathrm{R}^{2}=.501, \mathrm{~F}=3.87, p<0.0001\right)$. The variance explained was primarily attributable to the Parietal/Cerebellum metabolic ratio $\left(\mathrm{R}^{2}=.335, \mathrm{~F}=4.79, p<0.037\right)$.

Because of the more rapid parietal, as compared to frontal, decrement in cortical function in early Alzheimer's disease $(11,29)$, we anticipated a positive correlation between the P300 latency Z-scores and a Frontal/Parietal PET ratio in these patients. This correlation was not significant.

Relationships between PET ratios and P300 latency were also tested within the pAD group alone. P300 latency Z-score was correlated significantly with Frontal/Cerebellum metabolic ratio $(\mathrm{r}=-.49, p<0.02)$, but not with those from other brain regions.

\section{DISCUSSION}

The results of this study demonstrate that P300 latency is one measure sensitive to the functional status of cerebral association cortex, especially the parietal region and, to a lesser degree, frontal and temporal areas. It is noteworthy that this association was observed in early stage AD patients and controls.

The high rate of correct classification in this study $(89 \%)$ as compared to others in the literature [(14), 80\%; (3), 72\%; (48), $83 \% ;(17), 79 \%$; $(35), 31 \%]$ may in part reflect the extensive selection procedures, including thorough screening for other possible etiologies of cognitive decline. Also contributing to successful discrimination was the strong association between P300 latency and the functional status of the cortical tissue most at risk in early Alzheimer type dementia. Thus studies using mixed groups or other types of dementia, e.g., multiinfarct, Parkinson's, and Huntington's patients, have yielded lower discrimination rates, perhaps due to less consistent involvement of cortical association regions in these disorders.

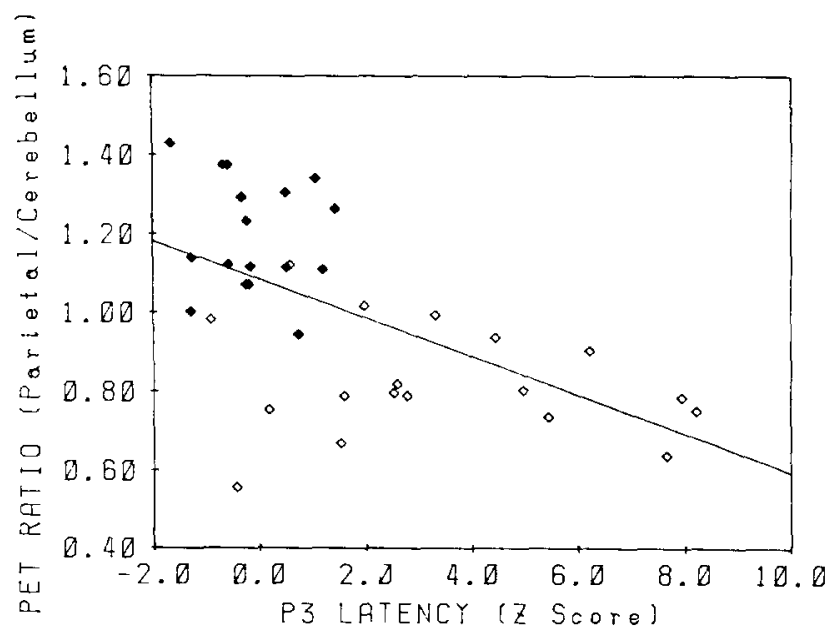

FIG. 4. Scatterplot of the relationship between P3 Z-score and parietal metabolic rate divided by cerebellum metabolic rate for normal controls (solid diamonds) and pAD patients (open diamonds). The line represents the regression function: $\mathrm{Pt} / \mathrm{Cb}$ rate $=1.084-(0.049 \times \mathrm{P3} \mathrm{Z}$-score $)$. 
While P300 latency discriminated between early Alzheimer's patients and controls, it does not differentiate between questionable and mild stages of dementia (Fig. 2; CDR 0.5 and CDR 1.0). There is, however, evidence that P300 latency is sensitive to the degree of dementia when a wider range of cognitive decline is considered $(4,18,31,39)$. P300 latency, as a measure of perceptual processing speed, represents only one facet of the many cognitive abilities summarized in the CDR or MMS. While various mental abilities are relatively well correlated over broad functional ranges, within more narrowly defined groups, such as CDR 0.5 and 1.0 , these abilities may not be strongly associated. An alternative hypothesis for the lack of association between P300 latency and CDR or MMS in PAD patients would propose that P300 latency is more sensitive to individual differences in general cognitive ability than either CDR or MMS within the early stages of AD.

The strong association of $\mathrm{P} 300$ latency with the functional status of parietal association cortex is consistent with what is known about both the cognitive processes related to P300 latency (i.e., perceptual recognition time), and those cognitive processes which depend heavily on the participation of the parietal cortical region (i.e., perceptual discrimination and recognition). Considerable evidence supports the notion that $\mathrm{P} 300$ latency is prolonged by increasing task difficulty in such a way as to require greater depth of stimulus processing $(5,8,10,15,27,30,44,45,47)$. Since the importance of parietal cortex, particularly in the temporal-parietal-occipital (TPO) region, in information processing is well established $(6,22,26,32,33)$, the sensitivity of P300 latency to compromised functioning of this region is not surprising.

Evidence is also accumulating linking P300 to some aspects of memory function $(24,40,49)$. For example, Polich et al. (40) have reported an association between P300 latency and immediate memory of numbers in the Digit Span test in normal individuals. Significant correlations were found in the subjects of our study between P300 latency and a number of neuropsychological tests of memory function. Thus, prolonged P300 latency and decreased function in the TPO area may be associated with memory decline. Impaired memory is one of the earliest and most prominent features of Alzheimer type dementia.

It should be emphasized that these data do not bear on the issue of the neural generators of the $\mathrm{P} 300$ wave. Rather, they reveal aspects of the neural systems required for the rapid and efficient information processing reflected in a short latency P300. Efficient processing in parietal cortex would, thus, be a necessary contributor to the elicitation of a normal latency P300, which itself may be generated in other neural tissue.

The dependence of P300 latency on the level of parietal lobe functioning suggested in these data must be considered in the light of abnormally prolonged $\mathrm{P} 300$ latencies in patients with primarily subcortical neurological disorders, i.e., Parkinson's disease and Huntington's disease $(18,19)$. In the case of these subcortical dementias, latencies of earlier components, particularly N1 and $\mathrm{P} 2$, are also delayed along with the P300. In Alzheimer's patients these early waves have normal latencies and the later P300 is specifically delayed (12). As indicated in the results, this was also the case for the pAD patients in this study. Thus, while delayed P300 latency in subcortical dementia might be characterized as a "downstream" effect of changes in earlier stages of processing, in Alzheimer's dementia P300 latency appears to be a more specific reflection of the integrity of the parietal cortex.

Finally, we believe that these results bear on the possible clinical utility of a P300 latency measure. Our results suggest that P300 latency can be used as a one-directional clinical test in which normal latency cannot be said to rule out the presence of dementing illness, but prolonged latency would suggest a high probability of dementia. Although the relationship should be tested in other dementias, prolonged P300 latency, together with normal latency of earlier components, appears to be an index of the declining functional status of cortical association tissue, particularly of the parietal lobe. Increase in P300 latency would thus be a reflection of the compromised status of a specific brain system, rather than type of dementing disease.

\section{REFERENCES}

1. Bail, S. S.; Marsh, J. T.; Schubarth, G.; Brown, W. S.; Strandburg, R. Longitudinal P300 changes in Alzheimer's disease. J. Gerontol; in press.

2. Beck, E. C.; Swanson, C.; Dustman, R. E. Long latency components of the visually evoked potential in man: effects of aging. Exp. Aging Res. 6:523-545; 1980.

3. Brown, W. S.; Marsh, J. T.; LaRue, A. Event-related potentials in psychiatry: differentiating depression and dementia in the elderly. Bull. Los Angeles Neurol. Soc. 47:91-107; 1982.

4. Brown, W. S.; Marsh, J. T.; LaRue, A. Exponential electrophysiological aging: P3 latency. Electroencephalogr. Clin. Neurophysiol. 55:277-285; 1983.

5. Coles, M. G. H.; Gratton, G.; Bashore, T. R.; Eriksen, C. W.; Donchin, E. A psychophysiological investigation of the continuous flow model of human information processing. J. Exp. Psychol. [Hum. Percept.] 11:529-553; 1985

6. Critchley, M. The partietal lobes. London: Arnold; 1953.

7. deLeon, M. J.; George, A. E.; Ferris, S. H. Computed tomography and positron emission tomography: correlates of cognitive decline in aging and senile dementia. In: Poon, L. W., ed. Handbook for clinical memory assessment of older adults. Washington, DC: American Psychological Association; 1986:367-382.

8. Duncan-Johnson, C. C.; Donchin, E. On quantifying surprise: the variation of event-related potentials with subjective probability. Psychophysiology 14:456-467; 1977.

9. Folstein, W. F.; Folstein, S. E.; McHugh, P. R. 'Mini-Mental State': A practical method for grading the cognitive state of patients for the clinician. J. Psychiatr. Res. 12:189-198; 1975.

10. Ford, J. M.; Roth, W. T.; Mohs, R. C.; Hopkins, W. F.; Kopell, B.
S. Event-related potentials recorded from young and old adults during a memory retrieval task. Electroencephalogr. Clin. Neurophysiol. $47: 450-459 ; 1979$.

11. Friedland, R. P.; Budinger, T. F.; Ganz, E.; Yano, Y.; Mathis, C. A.; Koss, B.; Ober, B. A.; Huesman, R. H.; Derenzo, S. E. Regional cerebral metabolic alterations in dementia of the Alzheimer type: positron emission tomography with [18F] fluorodeoxyglucose. J. Comput. Assist. Tomogr. 7:590-598; 1983.

12. Goodin, D. S.; Aminoff, M. J. Electrophysiological differences between subtypes of dementia. Brain 109:1103-1113; 1986.

13. Goodin, D. S.; Squires, K. C.; Henderson, B. H.; Starr, A. Age-related variations in evoked potentials to auditory stimuli in normal human subjects. Electroencephalogr. Clin. Neurophysiol. 44:447-458; 1978 .

14. Goodin, D. S.; Squires, K. C.; Starr, A. Long latency event-related components of the auditory evoked potential in dementia. Brain 101:635-648; 1978 .

15. Goodin, D. S.; Squires, K. C.; Starr, A. Variations in early and late event-related components of the auditory evoked potential with task difficulty. Electroencephalogr. Clin. Neurophysiol. 55:680-686; 1983.

16. Goodin, D.; Starr, A.; Chippendale, T.; Squires, K. Sequential changes in the P3 component of the auditory evoked potiental in confusional states and dementing illnesses. Neurology 33:1215-1218; 1983.

17. Gordon, E.; Kraiuhin, C.; Stanfield, P.; Meares, R.; Howson, A. The prediction of normal P3 latency and the diagnosis of dementia. Neuropsychologia 24:823-830; 1986.

18. Hansch, E. C.; Syndulko, K.; Cohen, S. N.; Goldberg, Z. I.; Potvin, A. R.; Tourtellotte, W. W. Cognition in Parkinson's disease: an 
event-related potential perspective. Ann. Neurol. 11:599-607; 1982.

19. Hansch, E. C.; Syndulko, K.; Cohen, S. N.; Tourtellotte, W. W.; Potvin, A. R. Event-related potentials in Huntington's disease: preliminary data. Bull. Los Angeles Neurol. Soc. 46:61; 1981.

20. Hawkins, R. A.; Mazziotta, J. C.; Phelps, M. E.; Huang, S. C.; Kuhl, D. E.; Carson, R. E.; Metter, E. J.; Riege, W. H. Cerebral glucose metabolism as a function of age in man: influence of the rate constants in the fluorodeoxyglucose method. J. Cereb. Blood Flow Metab. $3: 250-253 ; 1983$.

21. Hayes, W. L. Statistics for the social sciences. 2nd ed. New York: Holt, Rinehart and Winston; 1973:661.

22. Hecaen, H.; Albert, M. Human neuropsychology. New York: John Wiley and Sons; 1978.

23. Hughes, C. P.; Berg, L.; Danziger, W. L.; Cohen, L. A.; Martins, R. L. A new clinical scale for staging of dementia. Br. J. Psychiatry 140:556-572; 1982.

24. Karis, D.; Fabiani, M.; Donchin, E. P300 and memory: individual differences in the von Restorff effect. Cogn. Psychol. 16:177-216; 1984.

25. Klinger, A.; deLeon, M. J.; George, A. E.; Miller, J. D.; Wolf, A. P. Elevated cerebellar glucose metabolism in microvascular white matter disease: normal aging and Alzheimer's disease. J. Cereb. Blood Flow Metab. 8:433-435; 1988.

26. Kolb, B.; Whishaw, I. Fundamentals of human neuropsychology. 2nd ed. New York: Freeman; 1985.

27. Kramer, A. F.; Donchin, E. Brain potentials as indices of orthographic and phonological interaction during word matching. J. Exp. Psychol. [Learn. Mem. Cogn.] 13:76-86; 1987.

28. Kuhl, D. E.; Metter, E. J.; Riege, W. H. Patterns of cerebral glucose utilization in depression, multiple infarct dementia, and Alzheimer's disease. In: Sokoloff, L., ed. Brain imaging and brain functions. New York: Raven Press; 1985:211-226.

29. Kuhl, D. E.; Metter, E. J.; Riege, W. H.; Hawkins, R. A. Determinations of cerebral glucose utilization in dementia using positron emission tomography. Dan. Med. Bull. 32:51-55; 1985.

30. Kutas, M.; McCarthy, G.; Donchin, E. Augmenting mental chronometry: the P300 as a measure of stimulus evaluation time. Science 197:792-795; 1977.

31. Lai, J. A.; Brown, W. S.; Marsh, J. T.; LaRue, A. Covariation of P3 latency and Mini-Mental State scores in geriatric patients. Psychophysiology 20:455; 1983.

32. Luria, A. The working brain. New York: Penguin; 1973.

33. Luria, A. Higher cortical functions in man. 2nd ed. New York: Basic Books; 1980

34. Pfefferbaum, A.; Ford, J, M.; Wenegrat, B. G.; Roth, W. T.; Kopell, B. S. Clinical application of the P3 component of event-related potentials. I. Normal aging. Electroencephalogr. Clin. Neurophysiol. 59:85-103; 1984.
35. Pfefferbaum, A.; Wenegrat, B. G.; Ford, J. M.; Roth, W. T.; Kopell, B. S. Clinical application of the P3 component of event-related potentials. II. Dementia, depression, and schizophrenia. Electroencephalogr. Clin. Neurophysiol. 59:104-124; 1984.

36. Phelps, M. E.; Huang, S. C.; Hoffman, E. J.; Selim, C. S.; Sokoloff, L.; Kuhl, D. E. Tomographic measurement of local cerebral glucose metabolic rate in humans with (F-18)2-fluoro-2-deoxy-D-glucose: validation of method. Ann. Neurol. 6:371-388; 1979.

37. Phelps, M. E.; Mazziotta, J. C. Positron emission tomography: human brain function and biochemistry. Science 228:799-809; 1985.

38. Picton, T. W.; Stuss, D. T.; Champagne, S. C.; Nelson, R. F. The effects of age on human event-related potentials. Psychophysiology 21:312-325; 1984.

39. Polich, J.; Ehlers, C. L.; Otis, S.; Mandell, A. J.; Bloom, F. E. P300 latency reflects the degree of cognitive decline in dementing illness. Electroencephalogr. Clin. Neurophysiol. 63:138-144; 1986.

40. Polich, J. L.; Howard, L.; Starr, A. P300 latency correlates with digit span. Psychophysiology 20:665-669; 1983.

41. Polich, J.; Howard, L.; Starr, A. Effects of age on the P300 component of the event-related potential from auditory stimuli: peak definition, variation, and measurement. J. Gerontol. 40:721-726; 1985.

42. Riege, W. H.; Metter, E. J. Cognitive and brain imaging measures of Alzheimer's disease. Neurobiol. Aging 9:69-86; 1988.

43. Riege, W. H.; Metter, E. J.; Kuhl, D. E. Correlation of memory and brain glucose metabolism in depression and probable Alzheimer's disease. J. Cereb. Blood Flow Metab. 5:S125-S126; 1985.

44. Ritter, W.; Simson, R.; Vaughan, H. G. Event-related potential correlates of two stages of information processing in physical and semantic discrimination tasks. Psychophysiology 20:168-179; 1983.

45. Sanquist, T. F.; Rohrbaugh, J. W.; Syndulko, K.; Lindsley, D. B. Electrocortical signs of levels of processing: perceptual analysis and recognition memory. Psychophysiology 17:568-576; 1980.

46. Sokoloff, L.; Reivich, M.; Kennedy, C.; Des Rosiers, M. H.; Patlak, C. S.; Pettigrew, K. D.; Sakurada, O.; Shinohara, M. [14C]Deoxyglucose method for the measurement of local cerebral glucose utilization: theory, procedures and normal values. J. Neurochem. 28:897-916; 1977.

47. Squires, N. K.; Donchin, E.; Squires, K. C.; Grossberg, S. Bisensory stimulation: inferring decision-related processes from the P300 component. J. Exp. Psychol. [Hum. Percept.] 3:299-315; 1977.

48. Syndulko, K.; Hansch, E. C.; Cohen, S.N.; Pearce, J. W.; Goldberg, Z.; Montan, B.; Tourtellotte, W. W.; Potvin, A. R. Long-latency event-related potentials in normal aging and dementia. In: Courjan, J.; Mauguiere, F.; Revol, M., eds. Clinical application of evoked potentials in neurology. New York: Raven Press; 1982:279-285.

49. Warren, L. R. Evoked potentials correlates of recognition memory. Biol. Psychol. 11:21-35; 1980. 